\title{
HYBRID LAYER THICKNESS IN PRIMARY AND PERMANENT TEETH - A COMPARISON BETWEEN TOTAL ETCH ADHESIVES
}

\author{
Natalia Gateva, Rossitza Kabaktchieva \\ Department of Pediatric Dentistry, Faculty of Dental Medicine, \\ Medical University, Sofia, Bulgaria
}

\section{SUMMARY}

Purpose: The aim this study is to compare the hybrid layer thickness and its micromorphological characteristics in samples from primary and permanent teeth following application of total etch adhesives.

Materials and methods: On intact specimens of 20 primary and 10 permanent teeth was created flat dentin surfaces. The patterns were divided in 6 groups. Two different total etch adhesive systems were used - one tree steps (OptiBond, Kerr) and one two steps (Exite, VivaDent). In groups 3, 4, 5 and 6 recommended etching time was used - $15 \mathrm{~s}$, in groups 1 and 2 the etching time was reduced to 7 s. After applying the adhesive, resin composite build-ups were constructed. Thus restored samples are stored in saline solution for 24 hours at temperature $37^{\circ} \mathrm{C}$. Then they are subjected to thermal stress in temperature between $5^{\circ} \mathrm{C}$ to $55^{\circ} \mathrm{C}$ for 1,500 cycles and to masticatory stress $-150,000$ cycles with force $100 \mathrm{~N}$ in intervals of $0.4 \mathrm{~s}$. After that the teeth are cut through the middle in medio-distal direction with a diamond disc. SEM observation was done to investigate the thickness of the hybrid layer and the presence of microgaps. Statistical analysis was performed with ANOVA and Tukey's tests.

Results: SEM observation showed significant differences of the hybrid layer thickness between primary and permanent teeth under equal conditions and after different etching time. Group 6 presented the highest average thickness $8.85 \mathrm{~m}$ and group 1 the lowest average in hybrid layer $3.74 \mathrm{~m}$.

Conclusion: In primary teeth the hybrid layer thickness increases with the increased etching time. The hybrid layer thickness in primary teeth is greater than that of the hybrid layer in permanent teeth under equal conditions. For primary teeth it is more appropriate to reduce the etching time to $7 \mathrm{~s}$ to obtain a hybrid layer with better quality.

Key words: primary teeth, permanent teeth, hybrid layer, total etch adhesive, etching time

\section{INTRODUCTION}

Adhesion to dental structures is based on a process, where inorganic dental structure is replaced by synthetic resin $(34,37)$. This process includes two phases. The first one is represented by elimination of calcium phosphates and with creation of micropores on the surfaces of the enamel and the dentine. The second one, the so called hybridization phase, is represented by infiltration and subsequent polymerization of the resin into created superficial micropores $(1,4,37)$. Both phases facilitate the bonding of the adhesive onto the dental structure. Adhesive penetrates into the dentine following, or parallel with its chemical processing (conditioning). This adhesive forms an intermediate layer, called hybrid layer $(1,24)$. Thus hybridization is a process of micromechanical interlocking, which provides demineralization, infiltration and polymerization, and was first described by Nakabayashi et al $(17,34)$. The hybrid layer is covered by a thin layer of adhesive, to which the composite is bonded $(1,24)$.

The application protocol of total etch adhesives includes as a separate step the application of acid to remove the smear layer and the smear plugs. At the same time the dentine is demineralized $0.5-0.75 \mathrm{~mm}$ of depth. Peritubular dentine is removed, which leads to enlargement of the dentine tubuli, and their orifices become funnel-like $(4,20$, $33,35,36)$.

It is followed by demineralization of the in peritubular dentine and a network of collagen fibres is revealed, so that such hybrid layer can be formed $(12,15$, $18,19,35,38)$.

The acids used for etching of the dentine surface remove the smear layer much faster in primary than in permanent teeth $(10,18,19,20,26,27,39)$, by causing deeper demineralization in primary teeth $(20)$. The reason for that is the difference in the chemical composition and reactivity of the primary teeth dentine as compared to the dentine of permanent ones $(14,18,19,20,23)$, so the buffering capacity of the mineral phase is smaller. The dentine of primary teeth is less mineralized, therefore it has a weaker neutralizing effect of the mineral phase, which in turn determines reduced buffer capacity to action of acids 
as compared to permanent teeth. It is established that longer etching results in formation of a thicker hybrid layer $(7,8)$ and facilitates the creation of unstable demineralized zone in the hybrid layer, which leads to reduction of bonding strength $(6,18,19,26)$. It is the quality, not the thickness of the formed hybrid layer, that is important for the strength of the bonding with the dentine. Therefore a thicker hybrid layer does not mean greater adhesive bond strength $(2,7$, $8,18,19,22,28,30,31)$.

The aim of this study is to compare the hybrid layer thickness and its micromorphological characteristics in samples from primary and permanent teeth following application of total etch adhesives.

The following tasks were therefore laid down:

- To measure the hybrid layer thickness in samples from both dentitions after $15 \mathrm{~s}$ etching.

- To measure the hybrid layer thickness in primary teeth after $7 \mathrm{~s}$ etching

- To compare the hybrid layer thickness following different etching time, and between samples from both dentitions.

- To evaluated the resin dentin interfacial morphology in samples from both dentitions.

\section{MATERIALS AND METHODS}

The teeth were collected from healthy adults and children, after signed informed consent (from the parents for children) for the use of these teeth in the experiment. The primary teeth are extracted due to physiological changes or due to orthodontic testimony, and the permanent - due to periodontal problems.

Grouping of experimental samples. Thirty intact teeth (20 primary molars and 10 primary premolars and molars) were selected. The teeth were divided in 6 groups as shown on Table 1.

Table 1. Grouping of experimental samples.

\begin{tabular}{|c|c|c|c|l|}
\hline Group & Teeth & $\mathrm{N}$ & Etching time & Adhesive system \\
\hline Group 1 & Primary teeth & 5 & $7 \mathrm{~s}$ & OptiBond FL (Kerr) -3 steps-total etch \\
\hline Group 2 & Primary teeth & 5 & $7 \mathrm{~s}$ & Exite (Ivoclar,Vivadent) - 2 steps-total etch \\
\hline Group 3 & Permanent teeth & 5 & $15 \mathrm{~s}$ & OptiBond FL (Kerr) -3 steps-total etch \\
\hline Group 4 & Permanent teeth & 5 & $15 \mathrm{~s}$ & Exite (Ivoclar,Vivadent) - 2 steps-total etch \\
\hline Group 5 & Primary teeth & 5 & $15 \mathrm{~s}$ & OptiBond FL (Kerr) -3 steps-total etch \\
\hline Group 6 & Primary teeth & 5 & $15 \mathrm{~s}$ & Exite (Ivoclar,Vivadent) - 2 steps-total etch \\
\hline
\end{tabular}

Preparation of the dental surface. Using round turbine burr (ISO 806314001534012 for primary teeth and 806314001534014 for permanent teeth) and water cooling, a medio-distal cut is made through the central occlusal fissure. Depth of the cut is compatible with the size of the burr. The depth of the enamel and dentine to be removed from the occlusal surface is marked in advance, which allows for removal of relatively compatible layer of enamel and dentine for each of the experimental samples. A cut parallel to the occlusal surface is done with high-speed burr (ISO 806204108524835010) and under water cooling. The cut is made up to the controlled depth determined by the initial cut with the round burr. The surface is smoothed with a polishing disc. This leads to the formation of a smooth dentine surface, which is at compatible distance from the central fissure. Samples are observed with optic microscope OLYMPUS VANOX-T under zoom $25 \mathrm{x}$ to $100 \mathrm{x}$ to establish whether the enamel has been completely removed from the occlusal surface.

The exposed dental surface (enamel and dentine) is etched with $37 \%$ phosphoric acid for $7 \mathrm{~s}$ in groups 1 and 2 and for $15 \mathrm{~s}$ for groups $3,4,5,6$. After the etching the surface of the samples is washed with aerosol spray, and then dried with air for $5 \mathrm{~s}$ from a distance of $20-25 \mathrm{~cm}$.

All adhesive systems are applied according to manufacturer's instructions, except for groups 1 and 2, where the etching time is reduced from $15 \mathrm{~s}$ to $7 \mathrm{~s}$. Samples are restored with lightcuring composite (Tetric EvoCeram, Ivoclar Vivadent, shade A3), applied in two layers, each of $1.0 \mathrm{~mm}$. Each of the layers is lightcured for $40 \mathrm{~s}$ with lightcuring light (Coltolux75, Curing Light, Whaledent). Finally the restorations are polished with polishing discs (ISO 9687.900 140) and cups (ISO 658204030503 090). Thus filled samples are stored in saline solution for 24 hours at temperature $37^{\circ} \mathrm{C}$. Then they are subjected to thermal stress in temperature between $5^{\circ} \mathrm{C}$ to $55^{\circ} \mathrm{C}$ for 1,500 cycles (Temperaturwechsel ZAHN-PRUGERAT BT1 unit) and to masticatory stress $-150,000$ cycles with force $100 \mathrm{~N}$ in intervals of $0.4 \mathrm{~s}$. Stress tests were carried out in the Departament of Conservative Dental Treatment in the Medical University, Graz, Austria.

After removal of existing roots at the level of cementenamel junction, the teeth are cut through the middle in mesio-distal direction with a diamond disc (ISO 350514220 ) and water cooling. The samples are decalcified with $36 \%$ silicone-free phosphoric acid for $10 \mathrm{~s}$ and 
deproteinized with $5 \%$ hypochoride for $120 \mathrm{~s}$ in order to remove the observed surface from smears.

Preparation for SEM examination. Prepared samples are placed on aluminium discs. They are then covered in vacuum with golden powder in a media of argon-cathode atomization with JEOL JFC - 1200 Fine coater. Research was carried out with scanning electron microscope type JEOL JSM - 5510 SEM with 750x zoom. In order to observe the morphology of the adhesive and of the hybrid layer, photographs were done on the borderline surface between the adhesive and the dental structures.

Below are the criteria to establish the quality of the adhesive bond in teeth from both dentitions:

- Formation of hybrid and of adhesive layer

- The thickness of the hybrid layer is measured on the photos with graph paper and compasses in three points
- in both ends and in the middle of the photos. Results obtained in millimeters were converted to microns.

- Characteristics of the formed resin tags - form in the basis, at the hybrid layer

- Micromorphology of the hybrid layer - formation of micropores in the resin-dentin interface.

\section{RESULTS}

Groups 1 and 2

In those two groups were researches samples from deciduous molars. On teeth from group 1 was applied 3-step adhesive system OptiBond FL (Kerr). Samples were demineralized with $37 \%$ phosphoric acid for $7 \mathrm{~s}$. Adhesive system was applied according to manufacturer's instructions, only the etching time was shortened to 7s (fig. 1, 2, 3).
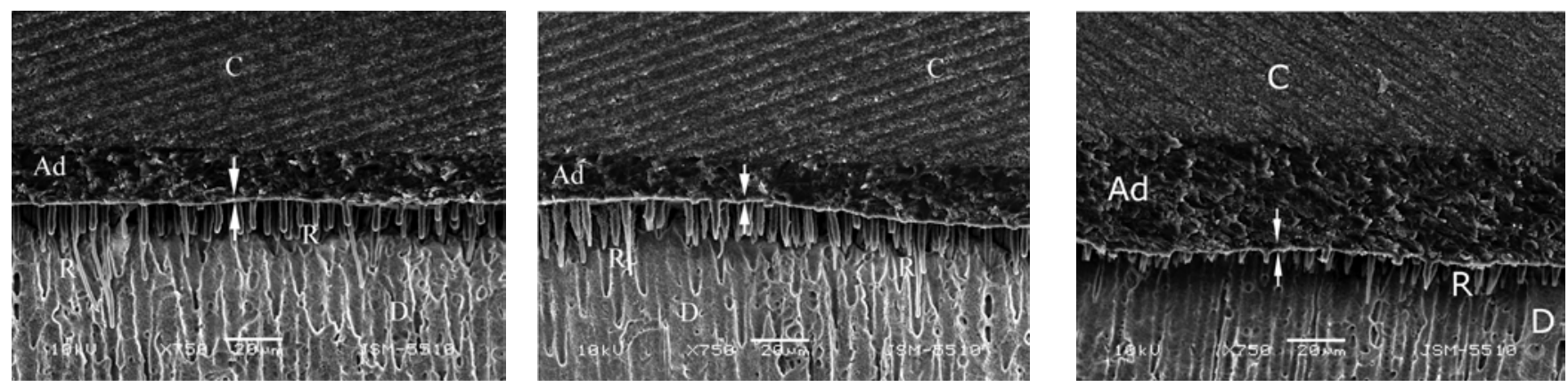

Fig. 1, 2 and 3. SEM of hybrid (between the arrows) and adhesive (Ad) layer in the borderline area in deciduous molar etched with $37 \%$ phosphoric acid for $7 \mathrm{~s}$ and adhesive system OptiBond FL (Kerr) (3-step, total etching). Multiple resin tags $(\mathrm{R})$ are observed in dentine $(\mathrm{D}), \mathrm{C}=$ composite.

Group 2 represents deciduous molars, in which following etching with $37 \%$ phosphoric acid, is applied adhesive system Exite (Ivoclar, Vivadent, 2-steps, total etching), according to manufacturer's instructions, and the time of the etching is reduced to $7 \mathrm{~s}$ (fig. $4,5,6$ ).
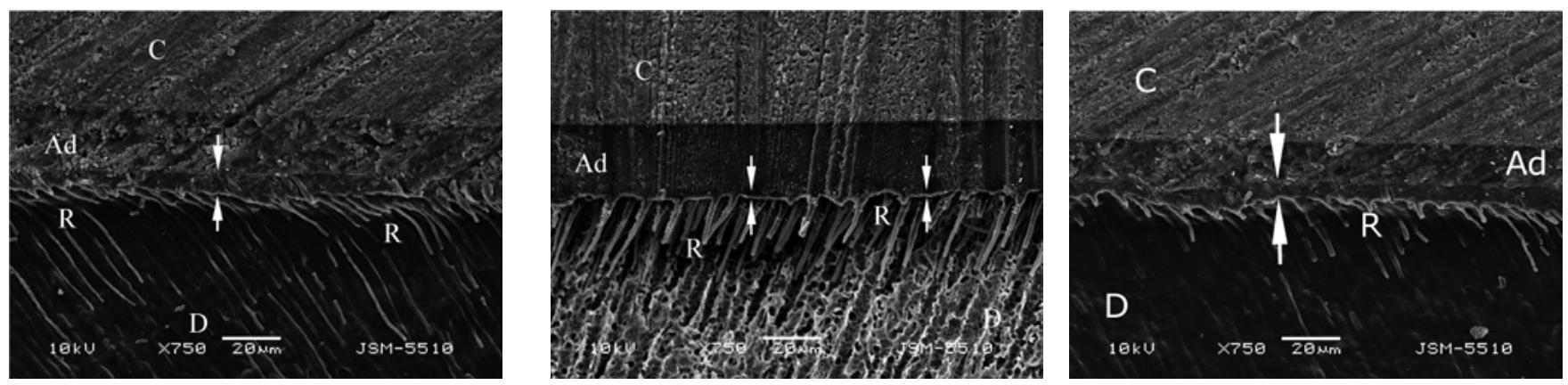

Fig. 4, 5 and 6. SEM of hybrid (between the arrows) and adhesive (Ad) layer within the dentine of deciduous molar, demineralised with 37\% phosphoric acid for 7s and adhesive system Exite (Ivoclar Vivadent, 2-steps, total etch). Multiple resin tags $(\mathrm{R})$ are observed in dentine $(\mathrm{D}) ; \mathrm{C}=$ composite. 
From the photographs analyzed it could be concluded that the thickness of the formed hybrid layer is greater in the samples from group 2. The hybrid layer in the samples from group 2 is more irregular, with varying thickness alongside. In the samples from both groups a significant number of resin tags with funnel shape are established, and they penetrate in depth into the dentine tubuli (fig. 1, 2, 3, 4, 5 and 6).
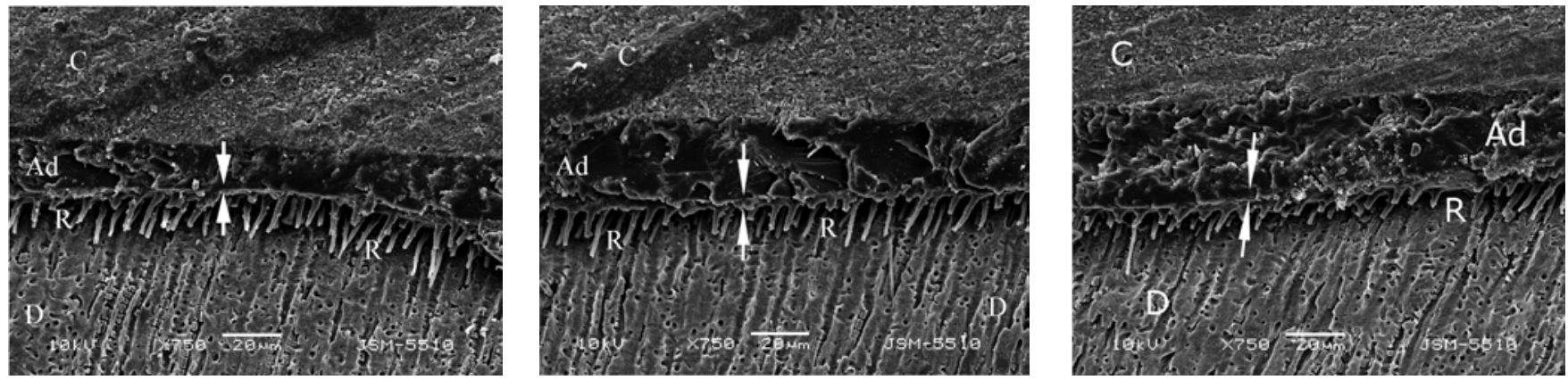

Fig. 7, 8, 9: SEM of hybrid (between the arrows) and adhesive (Ad) layer within the dentine of permanent molar, demineralized with $37 \%$ phosphoric acid for 15 s and adhesive system OptiBond FL (Kerr, 3-steps, total etch. Resin tags are observed (R) in dentine (D); C = composite.

In group 4 is used the fifth generation adhesive system Exite (Ivoclar Vivadent, 2-steps, total etch), applied according
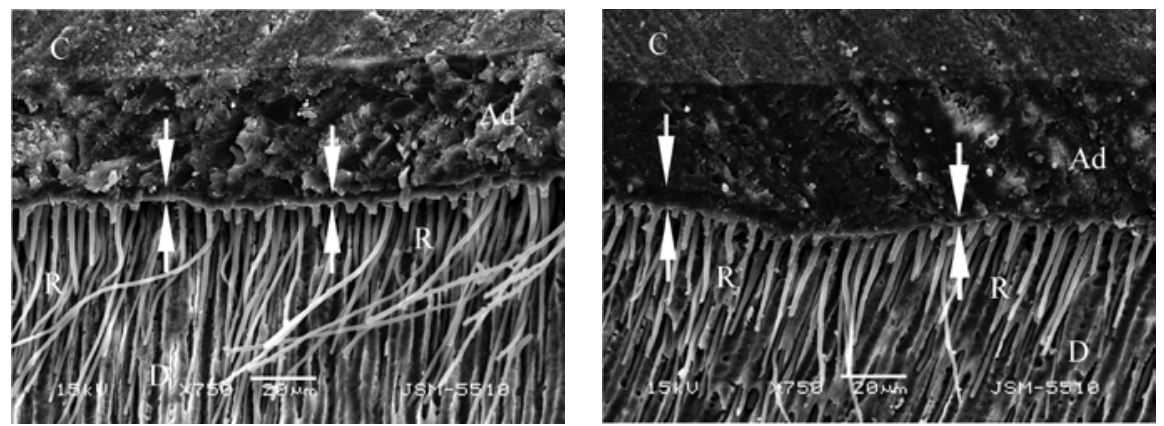

Groups 3 and 4

Groups 3 and 4 include samples of permanent teeth premolars and molars. In group 3 is used adhesive system OptiBond FL (Kerr, 3-steps, total etch). Adhesive system was applied according to manufacturer's instructions - etching for $15 \mathrm{~s}, 37 \%$ phosphoric acid is used (fig. 7, 8, 9).

Fig. 10, 11 and 12: SEM of hybrid (between the arrows) and adhesive (Ad) layer within the dentine in permanent molar, demineralised with 37\% phosphoric acid for 15s and adhesive system Exite (Ivoclar Vivadent, 2-steps, total etch). $\mathrm{R}=$ adhesive plugs, $\mathrm{D}=$ dentine, $\mathrm{C}=$ composite.

Photographs allow to observe the thickness of the adhesive and of the hybrid layer, which varies along the samples within a group, as well as between the samples from different groups (fig.7-12). The hybrid layer is thicker in samples from group 4 (fig.10-12) as compared to that from group 3 (fig.7-9). The thickness of the adhesive layer in the samples from group 4 (fig.10-12) is also greater than that of the samples from group 3 (fig.7-9). There is a number of resin tags with funnel shape, connected to the hybrid layer, which result from the intratubular hybridization. These resin tags are greater in number in the samples from group 4, and penetrate deeper into the dentine (fig.10-12 as compared to fig. 7-9). to manufacturer's instructions, following etching with $37 \%$ phosphoric acid for 15s (fig.10, 11, 12).

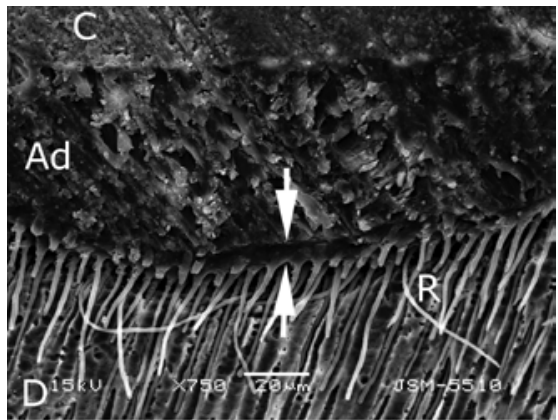

\section{Groups 5 and 6}

Group 5 consists of primary molars, in which is used the fourth generation adhesive system OptiBond FL (Kerr, 3steps, total etch) - the same as in groups 1 and 3. The dentine samples from primary teeth are etched for $15 \mathrm{~s}$ with $37 \%$ phosphoric acid. Group 5 allows a comparison of the thickness and of the micromorphology of the formed hybrid and adhesive layers with those of the samples from group 3, by the application of the same duration of etching of the dentine substrate (fig.13-15). 

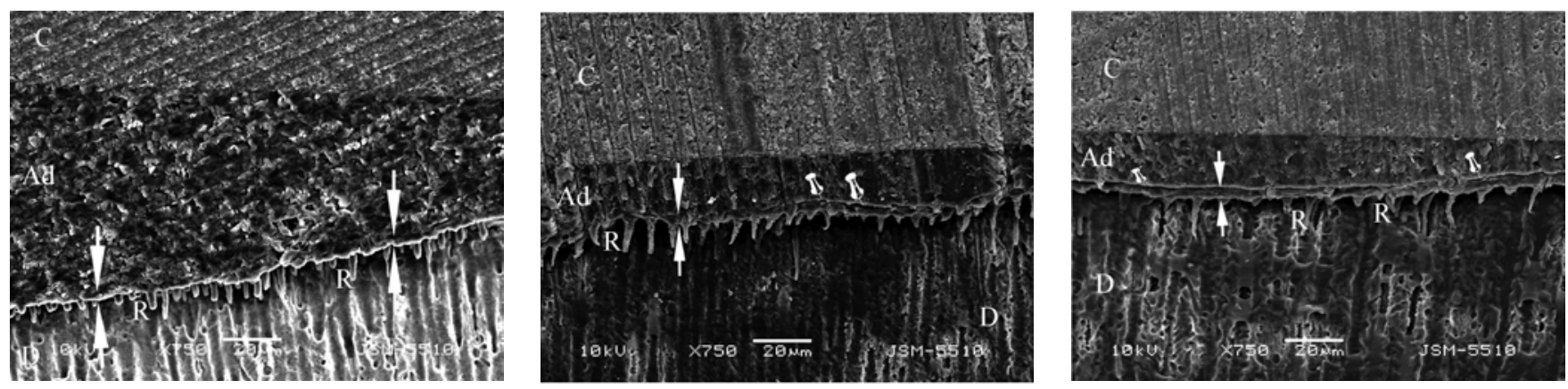

Fig. 13, 14 and 15: SEM of hybrid (between the arrows) and adhesive (Ad) layers in primary molar etched with $37 \%$ phosphoric acid for $15 \mathrm{~s}$ and adhesive system OpyiBond FL (Kerr, 3-steps, total etch). $\mathrm{C}=$ composite, $\mathrm{R}=\mathrm{resin}$ tags, $\mathrm{D}=$ dentine.

Group 6 consists of primary molars, in which is used the fifth generation adhesive system - Exite (Ivoclar Vivadent, 2-steps, total etch) - the same as in groups 2 and 4 . The dentine samples from primary teeth are etched for $15 \mathrm{~s}$ with $37 \%$ phosphoric acid. Group 6 allows for comparison of the

thickness and of the micromorhology and the formed hybrid and adhesive layer with those from the samples of group 4, by the application of the same duration of etching of the dentine substrate (fig.16-18).
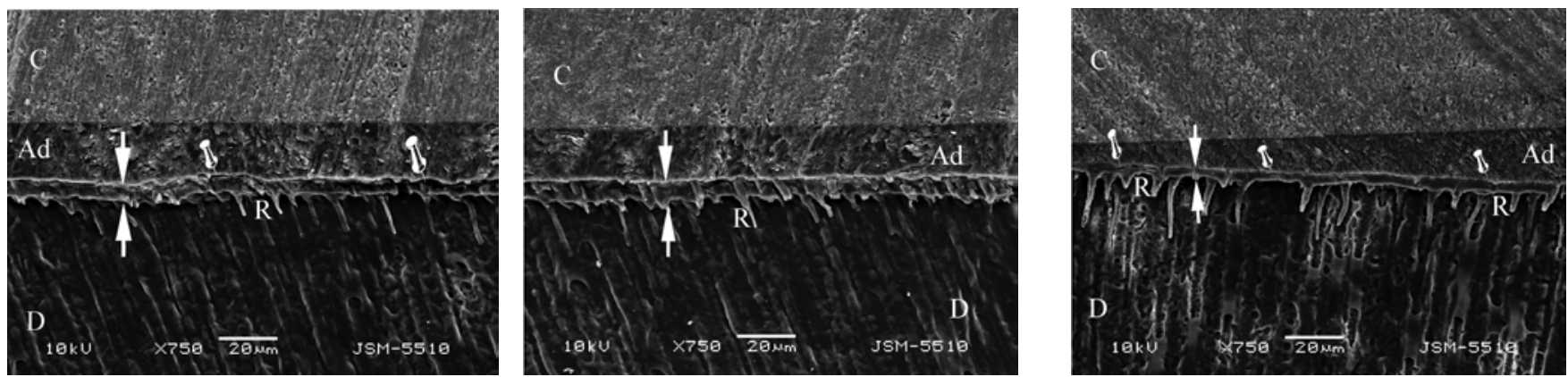

Fig. 16, 17 and 18: SEM of hybrid (between the arrows) and adhesive (Ad) layers in primary molar etched with $37 \%$ phosphoric acid for $15 \mathrm{~s}$ and adhesive system Exite (Ivoclar, Vivadent, 2-steps, total etch). $\mathrm{C}=$ composite, $\mathrm{R}=\mathrm{resin}$ tags, $\mathrm{D}=$ dentine.

The figures allow to establish that the thickness of the hybrid layer in both used generations of adhesive systems is different, as it is different between the samples from permanent teeth in groups 3 and 4 (fig.7-12), and is different between the samples from primary teeth in groups 5 and 6 (fig.13-18). When comparing the thickness of the hybrid layer within the dentine, it is established that it is thicker in the samples from groups 3 and 4 as compared to groups 5 and 6 (fig.7-18). Resin tags with funnel shape are observed in the samples from all groups. There are also microgaps between the hybrid and the adhesive layer in samples from group 5

(fig.14-15), and group 6 (fig.16 and 18).

By comparing the photographs of the samples from group 1 with group 5 (fig.1-3 and 13-15), as well as between those from group 2 (fig.4-6) with group 6 (fig.16-18) it is established that the hybrid layer is thicker, with microcracks in samples etched for 15s (fig.14-16 and fig. 18).

\section{Statystical analysis of the results}

Table 2 represents the average values of the measured thickness of the hybrid layer for different groups of samples and applied adhesive systems with total etching.

Table 2. Average values of the thickness of the hybrid layer (in microns) from adhesive systems with total etching in primary and permanent teeth.

\begin{tabular}{|l|c|c|c|}
\hline Group & Etching Time & Adhesive system & HL Thickness - average value (M) mean \pm SE \\
\hline Group 1 - primary teeth & $7 \mathrm{~s}$ & OptiBond FL & $3,74 \pm 0,32$ \\
\hline Group 2 - primary teeth & $7 \mathrm{~s}$ & Exite & $4,70 \pm 0,18$ \\
\hline Group 3 - permanent teeth & $15 \mathrm{~s}$ & OptiBond FL & $4,46 \pm 0,13$ \\
\hline
\end{tabular}




\begin{tabular}{|l|c|c|c|}
\hline Group $4-$ permanent teeth & $15 \mathrm{~s}$ & Exite & $7,36 \pm 0,56$ \\
\hline Group 5 - primary teeth & $15 \mathrm{~s}$ & OptiBond FL & $5,66 \pm 0,11$ \\
\hline Group 6 - primary teeth & $15 \mathrm{~s}$ & Exite & $8,85 \pm 0,41$ \\
\hline
\end{tabular}

The analysis of the results shows statistically significant difference in the thickness of the hybrid layer between the samples of different experimental groups (Table 3).

Table 3. Hybrid layer thickness in samples from experimental groups.

\begin{tabular}{|c|c|c|c|c|c|c|}
\hline Group & & & HL Thick & mean $\pm \mathrm{SD}$ & $\mathrm{t}$ & $\mathrm{P}$ \\
\hline Group 1 Group 2 & 5 & 5 & $3.74 \pm 0.32$ & $4.70 \pm 0.18$ & 5.84 & $<0.001^{*}$ \\
\hline Group 4 & 5 & 5 & $4.46 \pm 0.13$ & $7.36 \pm 0.56$ & 11.28 & $<0.0001 *$ \\
\hline Group 5 Group 6 & 5 & 5 & $5.66 \pm 0.11$ & $8.85 \pm 0.41$ & 16.80 & $<0.0001^{*}$ \\
\hline
\end{tabular}

*The difference is statistically significant.

In comparing the results for the thickness of the formed hybrid layer, it is established that there is a difference between samples from group 1 and group 2, between samples from group 3 and group 4, and also between samples from group 5 and group 6 (Table 3). A thicker hybrid layer is formed following application of 2-steps total etch adhesive system (Exite - groups 2, 4, and 6), as compared to application of 3-steps total etch adhesive (OptiBond FL - groups 1, 3 and $5)$. The difference in the measured mean thickness of the hybrid layer is statistically relevant between the pairs of groups (Table 3$)(\mathrm{p}<0.0001)$.

A comparison was made between the average values of the thickness of the hybrid layer for the combinations in pairs between experimental groups 1, 3, and 5 where we used comparison between the two dentitions with different etching time and the same adhesive system OptiBond FL (3-steps, total etching), by applying one-way ANOVA analysis (Table 4). All pairs are with confirmed statistical relevance of the differences in the values of the thickness of the hybrid layer (Table 4).

Table 4. Thickness of the hybrid layer in pairs of experimental groups 1, 3 and 5 and adhesive system OptiBond FL (Kerr).

\begin{tabular}{|l|c|c|c|c|c|}
\hline \multirow{2}{*}{ Group } & In comparison & Average Difference & \multicolumn{2}{|c|}{$95 \%$ confidential interval for mean } & \multirow{2}{*}{$\mathrm{P}^{*}$} \\
\cline { 3 - 5 } & with & in HL Thickness & Lower Bound & Upper Bound & \\
\hline Group 1 & Group 3 & -0.72 & -1.26 & -0.19 & $<0.0001$ \\
& Group 5 & -1.92 & -2.46 & -1.38 & $<0.0001$ \\
\hline Group 2 & Group 5 & -1.19 & -1.42 & -0.96 & $<0.0001$ \\
\hline
\end{tabular}

*Empirical level of statistical relevance (ANOVA).

It is established that there is statistically significant difference in the thickness of the hybrid layer in the group of primary teeth (groups 1 and 5) with different time for etching -7 and $15 \mathrm{~s}$, the greater thickness is measured in $15 \mathrm{~s}$ etching (group 5) $(\mathrm{p}<0.0001)$; there is statistically significant difference in the hybrid layer thickness with etching for $15 \mathrm{~s}$ between the samples from two dentitions (groups 3 and 5), with greater mean thickness of the hybrid layer measured in the samples from primary teeth (group 5) $(\mathrm{p}<0.0001)$; and statistically significant difference in the thickness of the hybrid layer between group 1 and group 3 with greater thickness of this layer established in permanent teeth (group 3) $(p<0.0001$ ) and using the same adhesive system OptiBond FL (Table 4).

The same comparison is also done between groups 2 , 4 and 6 in which was applied the 2-steps total etc adhesive system (Exite), by using one-way ANOVA analysis (Table 5). All pairs are with confirmed statistical significant of the differences in the values of the thickness of the hybrid layer (Table 5). 
Table 5. Hybrid layer thickness in pairs of experimental groups 2, 4, and 6 and adhesive system Exite.

\begin{tabular}{|c|c|c|c|c|c|}
\hline Group & In comparison & Average Difference & \multicolumn{2}{|c|}{$95 \%$ confidential interval for average } & \multirow{2}{*}{$\mathrm{P}^{*}$} \\
\cline { 3 - 5 } & with & in HL thickness & Lower Bound & Upper Bound & \\
\hline Group 2 & Group 4 & -2.65 & -3.59 & -1.71 & $<0.0001$ \\
& Group 6 & -4.14 & -4.83 & -3.46 & $<0.0001$ \\
\hline Group 4 & Group 6 & -1.49 & -2.44 & -0.53 & $<0.0001$ \\
\hline
\end{tabular}

*Empirical level of statistical relevance (ANOVA).

It is established that there is statistically significant difference in the thickness of the hybrid layer in the group of primary teeth (groups 2 and 6 ) with different time for etching -7 and $15 \mathrm{~s}$, the greater thickness is measured in $15 \mathrm{~s}$ etching (group 6$)(\mathrm{p}<0.0001)($ Table 5$)$; there is statistically significant difference in the hybrid layer thickness with etching for $15 \mathrm{~s}$ between the samples from two dentitions (groups 4 and 6), with greater thickness established in the samples from primary teeth (group 6) $(\mathrm{p}<0.0001)($ Table 5); and statistically significant difference in the thickness of the hybrid layer in group 2 (primary teeth) and group 4 $(p<0.0001)$ with greater thickness established in the samples from permanent teeth (group 4) and using the same adhesive system Exite (Table 5).

\section{DISCUSSION}

The samples from all experimental groups were restored with the mediation of adhesive systems belonging to Etch\&Rinse strategy for adhesion with dental structures. In them adhesion is achieved by the formation of a hybrid layer, or so called zone of internal diffusion of the adhesive in the demineralized dentine $(15,16,17,19)$.

Descriptive analysis of the figures we observed shows presence of formed adhesive and hybrid layers, resin tags with funnel-like shape, resulting from intratubular hybridization, and connected with the hybrid layer, and penetrating in various depth into the dentine (fig. 1-18). There are established differences in the thickness of the formed adhesive and hybrid layers, they are thicker in the samples where 2steps adhesive system was applied - groups 2, 4, and 6 respectively, and the formed resin tags are also greater number and penetrate deeper in the same groups (fig.4-6, 10-12, 1618). It is considered that the formed resin tags also enforce the strength of the bonding with the dentine. In adhesives with Etch\&Rinse the formed resin tags increase the total strength against shear bond strength.

There are established significant differences in the thickness and in the quality of the formed hybrid layer. In the samples from primary teeth etched for $15 \mathrm{~s}$ it is observed the presence of microgaps between the adhesive and the hybrid layer and the dentine, as well as microgars inside the hybrid layer (fig.14-16 and 18). This means that under equal conditions the same adhesive system leads to formation of hybrid layer with different characteristics in samples from primary and permanent teeth (fig.7-9 as compared with fig.1315, and fig.10-12 as compared with fig.16-18). At the same time in etching for $7 \mathrm{~s}$ the formed adhesive and hybrid layers are with similar characteristics (fig.1-6) with those from the samples of permanent teeth etched for 15s (fig.7-12) and it is very important that there are no microgaps in those layers.

For the dentine bond strength of paramount importance is the quality of the formed hybrid layer, not its thickness, so a thicker hybrid layer does not mean greater adhesive bond strength $(1,7,8,18,19,22)$.

The results from our research show that acid etching of the dentine of primary teeth with $37 \%$ phosphoric acid for $7 \mathrm{~s}$ (group 1 and 2) results in formation of a hybrid layer in all of the samples observed (fig.1-6).

Acid etching of primary teeth for $15 \mathrm{~s}$ (groups 5 and 6) results in formation of a hybrid layer with significantly greater thickness than that in the samples from groups 1 and 2 ( 7 s etching) $(\mathrm{p}<0.05)$, as well as in comparison with that in the groups with samples from permanent teeth - groups 3 and 4, etched for 15s (Table 3-5, fig.1-18). Similar to the results of a previous research of ours for the nature of the changes in the dentine following acid etching (5), this research also confirm the fact that the acid used is more aggressive on the primary dentine than on the dentine of permanent teeth, other conditions being equal. That leads to a deeper demineralization of the intertubular dentine and results in the formation of a significantly thicker hybrid layer in primary teeth (Table 4 and 5). There is a chance that such deeply demineralized dentine may not be completely impregnated by the adhesive systems and this creates risks of the formation of an uninfiltrated by the adhesive zone between the hybrid layer and the intact dentine structure. In that case the removed mineral matrix is not completely replaced by the primer of the adhesive system, which facilitates the penetration of the adhesive, there remains a more unstable zone in the basis of the hybrid layer, which is a possible route for micro- and nanopermeability, enzymic and hydrolytic decomposition and following all that - an area for failure of the bonding $(7,18$, $19,25,26)$. The reason for that are also likely to be the microcracks we observed in the samples from groups 5 and 6 (fig. 14-16 and 18).

Our research shows that the application of the same adhesive system with the same clinical protocol in primary and in permanent teeth leads to formation of adhesive and 
hybrid layer with different characteristics. They are with greater thickness in the samples from primary teeth. The values for the thickness of the hybrid layer are with statistically significant difference between the two dentitions, and with other conditions equal, the measured hybrid layer in primary teeth is thicker ( $<<0.05$, Table 2,4 and 5$)(2,18$, 19).

\section{Conclusions:}

Based on the results we obtained as well as on the results from the specialized literature, it could be accepted that:

1. In primary teeth the hybrid layer thickness increases with the increased etching time.

2. The greater thickness of the hybrid layer does not guarantee reliable and lasting adhesive bonding.

3. The hybrid layer thickness in primary teeth with the same concentration and duration of the etching is greater than that of the hybrid layer in permanent teeth.

4. For primary teeth it is more appropriate to reduce the etching time to $7 \mathrm{~s}$ to obtain a hybrid layer with better quality.

\section{REFERENCES:}

1. Bolanos-Carmona V, Gonzalez-Lopez $\mathrm{S}$, Briones-Lujan T, De Haro-Munoz C, de la Macorra JC. Effects of Etching Time of Primary Dentin on Interface Morphology and Microtensile Bond Strength. Dent Mater. 2006 Dec;22(12):1121-1129. [PubMed] [CrossRef]

2. Bolanos-Carmona V, Gonzalez-Lopez S, De Haro-Munoz C, Briones-Lujan MT. Interfacial Morphology and Bond Strength of Self-Etching Adhesives to Primary Dentin With or Without Acid Etching. J Biomed Mater Res B Appl Biomater. 2008 Nov;87(2):499-507. [PubMed] [CrossRef]

3. Eick JD, Gwinnett AJ, Pashley DH, Robinson SJ. Current Concepts on Adhesion to Dentin. Crit Rev Oral Bio Med. 1997; 8(3): 306-335. [PubMed] [CrossRef]

4. Eliades G, Watts DS, Eliades T. Dental hard tissues and bonding. Interfacial phenomena and related properties. Springer 2005, 89-122

5. Gateva N. Comparative SEM examinations of alterations on dentine surface of primary and permanent teeth after etching. Problemi na dentalnata medizina 2008; 34(1): 71-84. (in Bulgarian)

6. Hals E. Observation on Giant Tubules in Human Coronal Dentin by Light Microscopy and Microradiography. Scand J Dent Res. 1983 Feb;91(1):1-7 [PubMed]

7. Hashimoto M, Ohno H, Endo K, Kaga M, Sano H, Oguchi H. The Effect of Hybrid Layer Thickness on Bond Strength: Demineralized Zone of Hybrid Layer. Dent Mater. 2000 Nov;16(6):406-411. [PubMed]

8. Hashimoto M, Ohno H, Kaga M, Sano H, Tay FR, Oguchi H, et al: Overetching Effects on Micro-tensile Bond Strength and Failure Patterns for Two Dentin Bonding Systems. J Dent. 2002 FebMar;30(2-3):99-105. [PubMed]

9. Hosoya Y, Marshall SJ, Watanabe LG,
Marshall GW. Microhardness of Carious Deciduous Dentine. Oper Dent 2000 MarApr;25(2):81-89. [PubMed]

10. Koutsi V, Noonan RG, Horner JA, Simpson MD, Matthews WG, Pashley DH. The effect of Dentin Depth on the Permeability and Ultrastructure of Primary Molars. Pediatr Dent. 1994 Jan-Feb; 16(1):29-35. [PubMed]

11. Lohbauer U, Nikolaenko SA, Petschelt A, Frenkenberger R. Resin Tags do not Contribute to Dentin Adhesion in Selfetching Adhesives. J Adhes Dent. 2008 Feb;10(2):97-103. [PubMed]

12. Lopez GC, Baratieri VLN, Caldeira de Andrada MA, Vieira LCC. Dental adhesion: Present state of the art and future perspectives. Quintessence Int. 2002 Mar;33(3):213-224. [PubMed]

13. Mahoney E., Holt A., Swain M., Kilpatric N.: The Hardess and Modulus of Elasticity of Primary Molar Teeth: an Ultramicro-indentation Study. J Dent. 2000 Nov;28(8):589-594. [PubMed] [CrossRef]

14. Marquezan M, da Silveira BL, Burnett LH Jr, Rodrigues CR, Kramer PF. Microtensile Bond Strength of Contemporary Adhesives to Primary Enamel and Dentin. J Clin Pediatr Dent. 2007 Winter; 32(2):127-132. [PubMed]

15. Marshall GW Jr, Marshall SJ, Kinney JH, Balooch M. The Dentin Substrate: Structure and Properties Related to Bonding. J Dent. 1997 Nov;25(6):441458. [PubMed] [CrossRef]

16. Monksgaard EC. Wet or Dry, Normal or Deproteinized Dentin Surface as Substrate for Dentin Adhesives. Acta Odontol Scand. 2002 Jan;60(1):60-64. [PubMed]

17. Nakabayashi N., Kojima K., Masuhara E.: The promotion of adhesion by the infiltration of monomers into tooth substrates. J Biomed Mater Res. 1982 May;16(3):265-273. [PubMed]

18. Nцr JE, Feigal RG, Dennison JB, Edwards CA. Dentin Bonding: SEM Comparison of the Resin-Dentin Interface in Primary and Permanent Teeth. J Dent Res. 1996 Jun;75(6):1396- 1403. [PubMed]

19. Nor JE, Feigal RG, Dennison JB, Edwards CA. Dentin Bonding: SEM Comparison of the Dentin Surface in Primary and Permanent Teeth. Pediatr Dent. 1997 May-Jun;19(4);246-252. [PubMed]

20. Osorio R, Aguilera FS, Otero PR, Romero M, Osorio E, Garcya-Godoy F, Toledano M. Primary dentin etching time, bond strength and ultra-structure characterization of dentin surfaces. $J$ Dent. 2010 Mar;38(3):222-231. [PubMed] [CrossRef]

21. Pashley DH, Ciucchi B, Sano H, Carvalho RM, Russell CM. Bond strength versus dentine structure: A modelling approach. Arch Oral Biol. 1995 Dec; 40 (12):1109-1118. [PubMed] [CrossRef]

22. Perdigao J., Lopes M.: The Effect of Etching Time on Dentin Demineralization. Quintessence Int. 2001; 32: 19-26

23. Pioch T, Garsia-Godoy F, Duschner H, Koch MJ, Staehle HJ, Dorfer CE. Effect of cavity preparation instruments (oscillating or rotating) on the composite-dentin interface in primary teeth. Dental Materials 2003 Jun;19(4): 259-263. [PubMed] [CrossRef]

24. Rauch RU, Losche GM, Rosansky J, Roulet JF. Comparison of quantitative margin analysis and dye penetration. $J$ Dent Res. 1996; 75: abstr.187; 41

25. Sano H, Shono T, Takatsu T, Hosoda H. Microporous Dentin Zone Beneath Resin-Impregnated Layer. Oper Dent. 1994 Mar-Apr;19(2):59-64. [PubMed]

26. Sardella TN, de Castro FL, Sanabe ME, Hebling J. Shortening of Primary 
Dentin Etching Time and its Implication on Bond Strength. J Dent. 2005 May;33(5): 355-362. [PubMed] [CrossRef]

27. Shashikiran ND, Gunda S, Subba Reddy VV. Comparison of Resin-Dentin Interface in Primary and Permanent Teeth for Three Different Durations of Dentin Etching. J Indian Soc Pedod Prev Dent. 2002 Dec;20(4):124-131. [PubMed]

28. Spencer P, Wang Y, Walker MP, Swafford JR. Molecular Structure of AcidEtched Dentin Smear Layers - in situ Study. $J$ Dent Res. 2001 Sep;80(9):1802-1807. [PubMed] [CrossRef]

29. Spreafico D, Semeraro S, Mezzanzanica D, Re D, Gagliani M, Tanaka $\mathrm{T}$, et al. The effect of air-blowing step on the technique sensitivity of four different adhesive systems. J Dent. 2006 Mar;34(3): 237-244. [PubMed] [CrossRef]

30. Stadtler P: Dentinhaftmittel. Stomatologie 2007; 104(4): 101-109. [CrossRef]

31. Tulunoglu O, Tulunoglu I. Resindentin interfacial morphology and shear bond strengths to primary dentin after long- term water storage: An in vitro study. Quintessence Int. 2008 May;39(5): 427437. [PubMed]

32. Uekusa S, Yamaguchi K, Miyazaki M, Tsubota K, Kurokawa H, Hoyosa Y. Bonding efficacy of single-step self-etch systems to sound primary and permanent tooth dentin. Oper Dent. 2006 SepOct;31(5):569-576. [PubMed] [CrossRef]

33. Van Meerbeek B, Conn LJ Jr, Duke E, Eick J, Robinson S, Guerrero D. Correlative transmission electron microscopy examination of nondemineralized and demineralized rezin-dentin interfaces formed by two dentin adhesive systems. $J$ Dent Res. 1996 Mar;75(3):879-888. [Pubmed] [CrossRef]

34. Van Meerbeek B, De Munck J, Yoshida $\mathrm{Y}$, Inoue $\mathrm{S}$, Vargas $\mathrm{M}$, Vijay $\mathrm{P}$, et al. Buonocore memorial lecture. Adhesion to enamel and dentin: current status and future challenges. Oper Dent. 2003 MayJun;28(3):215-235. [PubMed]

35. Van Meerbeek B, Inokoshi S, Braem M, Lambrechts P, Vanherle G. Morphological aspects of the resin-dentin interdiffu- sion zone with different dentin adhesive systems. J Dent Res. 1992 Aug;71(8):15301540. [PubMed] [CrossRef]

36. Van Meerbeek B, Van Landuyt K, De Munck JD, Hashimoto M, Peumans M, et al. Technique-Sensitivity of Contemporary Adhesives. Dent Mater J. 2005 Mar; 24(1):1-13. [PubMed]

37. Van Meerbeek B., Vargas M., Inoue S., Yoshida Y., Peumans M Lambrechts P. et all.: Adhesives and cements to promote preservation dentistry. Operative Dentistry 2001; 6: 119-144

38. Wang Y, Spencer P. Analysis of Acid-Treated Dentin Smear Debris and Smear Layers Using Confocal Raman Microspectroscopy. J Biomed Mater Res. 2002 May;60(2):300-308. [PubMed]

39. Yaseen SM, Subba Reddy VV. Comparative evaluation of shear bond strength of two self-etching adhesives (sixth and seventh generation) on dentin of primary and permanent teeth: An in vitro study. J Indian Soc Pedod Prev Dent. 2009 Jan-Mar;27(1):33-38. [PubMed] [CrossRef]

\section{Corresponding author:}

Natalia Gateva

Department of Pediatric Dentistry, Faculty of Dentistry, Medical University, Sofia 1, St. Georgi Sofiiski str., 1431 Sofia, Bulgaria e-mail: nataliagateva@yahoo.de 